\title{
¿PARTICIPACIÓN O PACIFICACIÓN SOCIAL? \\ LA LÓGICA NEOLIBERAL EN EL CAMPO DE LA SALUD \\ INTERCULTURAL EN CHILE: EL CASO ATACAMEÑO ${ }^{1}$
}

Paola Bolados ${ }^{2}$

\section{* Introducción}

Resumen

En este artículo analizamos los nuevos mecanismos del poder burocrático implementados en Chile desde los años 90 a través de la apertura

de nuevos espacios de participación social. Se trata de atender a los procesos de etnogubernamentalización, democratización y neoliberalización que han operado en la construcción de nuevos campos de poder y saber, cuyo efecto principal ha resultado en una ampliación y profun-

dización del ámbito de intervención estatal en territorios indígenas como el atacameño. En este sentido, nos interesa mostrar etnográficamente cómo se ponen en marcha estos nuevos dispositivos de control y regulación sobre la población, específicamente a través de la creación de un Consejo de Desarrollo Local en salud (CDL), a mediados del año 2006, al interior de las estructuras del Consultorio General Rural de la comuna de San Pedro de Atacama.

Palabras claves: participación social - interculturalidad - neoliberalismo - etnogubernamentalidad.

This article analyzes the mechanisms of expansion of State power that, since the $1990_{s}$, intercultural policies have begun to push forward in Chile, through the constitution of new spaces for social participation. I aim to reveal those processes of ethnogovernamentality that have operated in the construction of new fields of power/knowledge, whose principal effect has been the widening and consolidation of State intervention over indigenous territory, such as the Atacameño. In this sense,

I seek to show, at an ethnographic level, the way these new devices of control and regulation over population are put into motion, specifically through the creation of the Council of Local Health Development, in mid 2006, within the structure of the General Rural Health Office of San Pedro de Atacama district.

Keys words: social participation - multiculturalism - neoliberalism ethnogovernmentality.

Recibido: julio 2008. Aceptado: enero 2009.
Después de casi dos décadas de dictadura militar en Chile (1973-1989), los gobiernos democráticos de la Concertación ${ }^{3}$ iniciaron un período caracterizado por la apertura de nuevos espacios de participación social. Estos fundamentalmente estuvieron dirigidos a poner en práctica los ejes de una nueva ingeniería social promovida por los organismos de desarrollo internacional, cuyos propósitos se dirigieron tanto a la democratización de la región, como al alivio de los efectos de pauperización que generaron las reformas neoliberales implementadas por el régimen. Este nuevo contexto económico, político y social, marcó el inicio de las primeras acciones del Estado chileno hacia las demandas de participación indígena dentro del aparato estatal, ya sea a través de programas sociales dirigidos a sectores rurales donde tradicionalmente han sido ubicados los grupos indígenas nacionales, así como mediante una política indígena y multicultural de amplio alcance implementada a comienzos del siglo XXI.

En este trabajo analizamos los nuevos mecanismos del poder burocrático desplegados en Chile desde los años 90 y los procesos de etnogubernamentalización, democratización y neoliberalización asociados a estos. La hipótesis que aquí desarrollamos, es que, a través de los espacios abiertos para la participación social e indígena se han ido estructurando nuevos campos de poder

\footnotetext{
${ }^{1}$ Este trabajo es parte de la investigación doctoral financiada con beca MECESUP y parte del proyecto FONDECYT 1070014: “La fábrica del multiculturalismo en Chile: Estado, etnodesarrollo y etnicidad en tiempos de globalización".

2 Universidad Católica del Norte. Gustavo Le Paige 380, San Pedro de Atacama, CHILE. Email: paobolados@yahoo.com.ar

3 Como "Concertación de Partidos por la Democracia" se reconoce en Chile a la coalición de partidos de centro-izquierda que lideraron la oposición al régimen militar y negociaron el retorno de la democracia a fines de los años 80 y comienzos de los 90 . Esta coalición, conformada principalmente por partidos políticos tradicionales como la Democracia Cristiana, el Partido Radical, el Partido Socialista y el nuevo Partido por la Democracia (PPD), es la que gobierna al país desde los años 90 hasta la actualidad.
} 
cuyo efecto principal, ha resultado en una ampliación y profundización del ámbito de intervención estatal en territorios indígenas como el atacameño (Figura 1).4 Etnográficamente mostramos los nuevos dispositivos de control y regulación sobre la población que operan vía la constitución, en el año 2006, de un Consejo de Desarrollo Local en salud ${ }^{5}$ en las estructuras formales del principal centro de salud de la comuna. En una primera parte, describimos las estrategias utilizadas por los agentes estatales de la salud para definir la participación social en el marco de la Reforma de la Salud y la política intercultural implementada por el Estado. En una segunda parte exponemos las resistencias generadas al interior del Consejo y la lucha de los agentes indígenas por apropiarse y redefinir la participación en términos diferentes a los propuestos o impuestos por el Estado. A partir de este período, el CDL es identificado como un espacio permanente de luchas por el control de las diferencias y el lugar privilegiado para reinscribir históricas demandas bajo categorías de etnicidad y multiculturalismo. En un tercera sección, examinamos el proceso de intervención estatal experimentado dentro del Consejo, el cual estuvo marcado por la incorporación de funcionarios regiona-

4 Actualmente, la atacameña constituye una de las siete poblaciones originarias reconocidas por la Ley Indígena de 1993, y se ubica geográficamente en la provincia del Loa, Región de Antofagasta en el norte de Chile. Según el último censo de 2002, un 4.6\% de la población total nacional se reconoció como indígena. De éste, $86 \%$ se reconoció mapuche, $7 \%$ aymara y 3\% atacameño. Este $3 \%$ equivale aproximadamente a 21000 habitantes, de los cuales, 66\% (cerca de 13000 habitantes) se concentra en la región de Antofagasta. De ese porcentaje, casi 80\% (cerca de 9000 habitantes) se concentra en la ciudad de Calama, siguiéndole San Pedro de Atacama como la comuna con mayor concentración de población originaria atacameña con 3000 habitantes aproximadamente. San Pedro de Atacama se constituyó como comuna durante el régimen militar en los años 80 y agrupó a las localidades de Río Grande, Toconao, Peine, Socaire, Talabre, Camar y San Pedro con sus ayllu. Una década después, el Estado chileno a través de su nueva política indígena reorganizó a las poblaciones originarias en Áreas de Desarrollo Indígena (ADI) a fin de focalizar sus acciones en sectores de alta concentración de población indígena. En el caso atacameño, el Área de Desarrollo Indígena Atacama La Grande se creó el año 1994 y consideró tanto a los poblados de la comuna de San Pedro de Atacama, como a localidades de la provincia del Alto Loa que actualmente pertenecen a la comuna de Calama. Sin embargo, posteriormente (año 2003), se crea otra ADI en el Alto Loa, la cual agrupará tanto a localidades que se reconocen atacameñas como a localidades que se identifican como quechuas.

5 De aquí en adelante nombrado como CDL o Consejo. les y autoridades municipales relacionadas con la salud quienes, desplegando dispositivos de invisibilización de los acuerdos tomados durante el tiempo de trabajo anterior, buscaron recuperar el control del espacio. En una cuarta y última sección, desarrollamos algunas ideas acerca de los efectos de este tipo de tácticas de "participación sin participación o participación impuesta" implementadas por el Estado. Principalmente nos referimos al nuevo tipo de poder político y económico que se comenzó a ejercer en territorios indígenas como al atacameño, donde la participación social se transformó tanto en una estrategia autoresponsabilizante de los sujetos respecto a su salud, como un factor de despolitización en el marco del multiculturalismo neoliberal implementado en Chile postdictadura.

\section{* La participación social en el nuevo contexto multicultural y democrático}

En el período postdictatorial, la participación emergió como uno de los íconos discursivos principales del proceso de democratización y en una estrategia alineada con la reconfiguración actual de la economía transnacional. Se transformó así en uno de los objetivos fundamentales de la política indígena de los últimos años y en la estrategia clave para compatibilizar "desarrollo con identidad" en los términos definidos por la Industria del Desarrolloencargada de financiar los programas sociales en América Latina (Breton 2003 Ms; Laurie at al. 2005). ${ }^{6}$ En el caso particular de Chile, la participación se constituyó en el emblema de lucha contra el régimen militar y en el discurso oficial de los partidos prodemocráticos utilizado para conquistar el poder y asegurar el triunfo en las urnas. Sin embargo, la discontinuidad y ruptura discursiva en el campo político cimentada en la oposición represión-dictadura/participación-democracia, no significó un cuestionamiento respecto al sistema económico implementado durante el gobierno militar, sino más bien implicó una continuidad del modelo y medidas parciales que afianzaron su desarrollo y consolidación (Schild

6 Nos referimos principalmente a organismos multilaterales como el Banco Mundial y el Banco Interamericano de Desarrollo, que en estas últimas décadas han dirigido sus inversiones al área de lo social, incorporando a su ámbito de intervención a los movimientos indígenas. Para el caso del Ecuador referirse a los trabajos de Breton (2003 Ms) y Laurie y colaboradores (2005). 


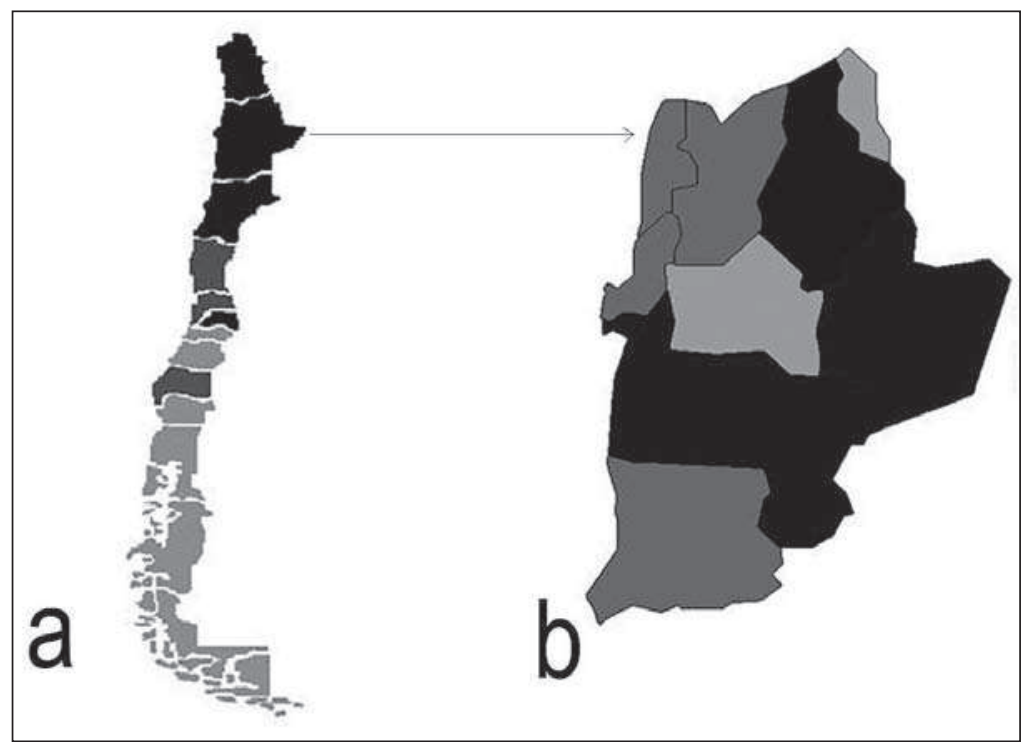

Figura 1. a) Mapa de Chile y sus regiones; b) Región de Antofagasta y sus comunas. En negro se señala la comuna de San Pedro de Atacama.

2000; Paley 2001). En este sentido, las políticas públicas de la década de los 90 se concentraron en mitigar los efectos de los ajustes económicos de los años 80 , dirigiendo sus acciones y programas hacia los sectores más afectados y socialmente más "conflictivos", ratificando el rol subsidiario del Estado y trasladando las responsabilidades estatales al campo privado y paraestatal. Los nuevos instrumentos jurídicos creados por la política indígena que dieron nacimiento a la Corporación Nacional de Desarrollo Indígena (CONADI) y a la organización de los habitantes originarios en Áreas de Desarrollo Indígena (ADI), constituyen los pilares legales para la apertura de estos espacios y el marco ideal para la creación de un nuevo campo burocrático. Además, y desde la política nacional en salud, se incentiva desde mediados de los años 90 la constitución de CDL, Comités de Salud Comunal o Consejos Consultivos en los centros de salud públicos, tales como hospitales, postas y consultorios. En este contexto, la creación del CDL emerge como resultado de complejos y heterogéneos procesos de activación de demandas étnicas promovidas por la política indígena y multicultural de los últimos 15 años.

La política multicultural en Chile se materializó con la implementación del Programa de Desarrollo Integral para Comunidades Indígenas, más conocido como Orígenes, el cual, con financiamiento del Banco Interamericano de Desarrollo (BID) y el gobierno de Chile, desplegó acciones en cuatro componentes: educación intercultural, salud intercultural, desarrollo productivo y fortalecimiento institucional de los servicios públicos y organizaciones comunitarias. Orígenes centró sus tareas en las poblaciones originarias aymara, atacameña y mapuche, y se estructuró en dos fases - (2001-2005) y (2006-2009)-, lo cual significó una inversión total de 113 millones de dólares distribuidos en 58 y 75 millones, respectivamente, para cada fase.

En el área de la salud, el programa a través de su "componente de salud intercultural" pretendió mejorar el acceso, la calidad y pertinencia cultural de la atención en los centros de salud en territorios cuya población fuera mayoritariamente indígena.7 A la vez, el componente buscó fortalecer la medicina indígena, como son denominadas actualmente las prácticas curativas existentes en las po-

\footnotetext{
7 El antecedente directo de este programa a nivel nacional es el Programa Especial Salud y Pueblos Indígenas del MINSAL (PESPI), el cual desde la segunda mitad de la década de los 90 se propuso reelaborar las políticas de salud pública y construir una Política de Salud y Pueblos Indígenas.
} 
blaciones originarias. Sin embargo, los problemas suscitados durante su implementación entre los años 2002 y 2006 , revelaron las dificultades para poner en práctica la participación social, especialmente cuando ésta aparece fuertemente apropiada por el Estado a través de sus instituciones y agentes. En el caso atacameño, fue la Mesa de Trabajo o Mesa de Salud promovida por Orígenes, la cual reunió a representantes de las diversas comunidades indígenas atacameñas y que, después de alcanzar un importante grado de involucramiento y movilización a nivel de las bases, experimentó la presión para su disolución y reconversión en una instancia formal en las estructuras de las ADI. En lo concreto, esta medida significó un desconocimiento del trabajo que venía efectuando la Mesa a nivel local así como la deslegitimación de sus representantes por parte de dirigentes y organismos estatales nucleados en la CONADI, el municipio y desde el propio Orígenes. Con estos antecedentes, el CDL emerge como un intento de activar la participación social en el territorio y como una estrategia de acercamiento entre los organismos estatales y la comunidad indígena local.

Paralelamente, la apertura de esta instancia coincide con otros tres importantes hitos en salud a nivel local: la inauguración de las nuevas dependencias del Consultorio General Rural dela comuna de San Pedrode Atacama, la constitución de la Asociación de Cultores y Colaboradores de la Medicina Ancestral Licanantay y Quechua $^{8}$ y la finalización de la primera fase del Programa Orígenes en el ADI Atacama La Grande, la cual desde su componente de salud intercultural, inicia las gestiones para implementar un Modelo de Atención

\footnotetext{
8 La Asociación de Cultores y Colaboradores de la Medicina Ancestral Licanantay y Quechua, se constituyó formalmente en el $1^{\text {er }}$ Encuentro Internacional y $4^{\circ} \mathrm{Nacional}$ de Medicina Indígena realizado en enero de 2006 en Caspana. Sin embargo, desde los inicios hubo cuestionamientos respecto a su legitimidad como organización por parte de los representantes del poder local y otros organismos del Estado. El primero se relacionó con la incorporación de miembros bajo la categoría de "colaboradores", que no eran sanadores indígenas. El segundo se vinculó a la forma jurídica bajo la cual se constituyó esta instancia. Es decir, la de una "asociación indígena" que según las autoridades estatales y paraestatales, contradecía las formas ancestrales de organización entre los sanadores indígenas, quienes hasta ahora no habían mostrado interés por trabajar en conjunto o compartir públicamente sus prácticas.
}

Intercultural en la comuna. ${ }^{9}$ Por su parte, la Reforma de la Salud iniciada en el año 2005 ya había incorporado la participación y la interculturalidad como ejes trasversales de su unidad de redes asistenciales, mientras que a nivel local, estas se transformaron en los objetivos programáticos durante el proceso de reestructuración de las ADI atacameñas. ${ }^{10}$ No obstante las condiciones favorables ofrecidas por el discurso estatal para la participación, el Consejo de Desarrollo Local irrumpió en un contexto altamente agitado por los efectos de la implementación de la política indígena y multicultural del Estado, la cual, como veremos, se tradujo en un debilitamiento y desarticulación de las organizaciones indígenas locales.

9 Estas gestiones también fueron impulsadas por Orígenes, al contratar los servicios de una consultora formada por dos institutos de investigación del norte de Chile. El proyecto consistió en sistematizar en un período de seis meses, la experiencia del parto aymara en el Hospital de Iquique, la experiencia de la red de asesores interculturales en Putre, y el diseño de un Modelo de Atención y Gestión en Salud Intercultural en la comuna de San Pedro de Atacama. En el caso atacameño, además, se solicitó un estudio epidemiológico que respaldara el tipo de modelo que debía implementarse, el cual por varios motivos, entre ellos la incompetencia técnica de la consultora, fue rechazado en tres oportunidades por las comunidades indígenas y los servicios estatales involucrados. Aunque la incapacidad técnica de la consultora para realizar un estudio epidemiológico fue una de las principales causas del fracaso del estudio, existieron otros elementos que señalaron esta "muerte anunciada". Me refiero específicamente a los problemas políticos entre los actores involucrados: por un lado, entre el Municipio, el Programa de Salud y Pueblos Indígenas y Orígenes mismo, los que se disputaron permanentemente el rol de fiscalización del proyecto; y por el otro, la ambigüedad del rol de los profesionales de la consultora, quienes mostraron un interés más bien económico que académico en su desempeño. En la evaluación final del proyecto, sin embargo, solo se consideraron las deficiencias técnicas, ignorando y desconociendo las presiones y tensiones políticas que ahogaron desde los inicios esta iniciativa. En síntesis, de 34 millones de pesos dos tercios se evaluaron perdidos (San Pedro y Putre) y sin resultados para el avance de la salud intercultural en esos territorios.

${ }^{10}$ Como parte de las estructuraciones en la política indígena local, ese mismo año el ADI Atacama la Grande, conformada desde 1994 por comunidades del Alto Loa y del Salar de Atacama, se subdividió y se creó una nueva ADI denominada Alto Loa. La segunda reestructuración consistió en la reorientación de los objetivos de las ADI hacia la participación e interculturalidad, producto del escaso involucramiento de las comunidades y organizaciones indígenas en la etapa anterior. 


\section{* "RAyando la cancha" desde la participación ESTATAL}

A mediados de 2006, el Consultorio General Rural de la comuna de San Pedro de Atacama invita a las diversas organizaciones, comunidades y asociaciones a conformar un nuevo espacio de "participación social". Los primeros encuentros organizados por el profesional del consultorio encargado de liderar el Consejo, estuvieron dirigidos a encuadrar este nuevo espacio, delineando sus objetivos y principales alcances. En la primera reunión, la participación fue definida como una estrategia de la Reforma de la Salud, la cual pretendía implementar un nuevo modelo de gestión en salud pública. Sus fundamentos fueron sintetizados de la siguiente manera:

"En el marco de la modernización de la gestión pública, la participación es concebida como una estrategia básica para la consolidación del sistema democrático, el logro del bienestary la inclusión e integración social [...]. La participación requiere, por una parte, que el sector público tenga la apertura, genere la información y establezca espacios y mecanismos que acojan las preocupaciones, necesidades y propuestas provenientes de la ciudadanía. Por otra parte, la participación necesita de una ciudadanía que se involucre en las cuestiones públicas, con organizaciones fuertes que representen toda su diversidad [...] desde el sector salud, la participación se considera un medio para el desarrollo de las personas como sujetos comprometidos con el cuidado de su salud y con el fortalecimiento de los servicios. Busca también la creación de comunidades con capacidad de interlocución que actúan solidariamente y ejerzan un control social sobre el sistema de salud" (presentación Power Point, reunión del CDL, agosto de 2006).

Desde esta perspectiva, la participación social fue, desde sus comienzos, relacionada a los procesos de democratización del sector público, la ampliación y ejercicio de nuevas formas de ciudadanía social y/o cultural, como en función del desarrollo y bienestar de la población vía su inclusión social. En los tres casos, se la concibe como un estado ideal de la sociedad y/o comunidad, el cual se alcanza fortaleciendo las redes sociales, delegando cierta autonomía y enfatizando un rol de fiscalización y control de la sociedad sobre la acción del Estado. Sin embargo, desde el inicio surgen las primeras interrogantes por parte de los representantes del Consejo sobre las condiciones y exigencias impuestas para su creación. La crítica va dirigida a la participación restringida ofrecida en el Consejo, la cual se limita a miembros de asociaciones y comunidades formalmente constituidas excluyendo así a una mayoría de "usuarios" del sistema que no se encuentran organizados. A su vez, emerge el cuestionamiento respecto al decreto que da origen al Consejo, el cual señala que esta instancia debe ser presidida por el director del consultorio, quien además goza de la atribución para elegir a un secretario ejecutivo.

Una vez delimitada la naturaleza y el ejercicio de la participación social desde la perspectiva estatal, prosiguió una segunda demarcación conceptual en relación a la noción de interculturalidad. La reflexión del coordinador del Consejo fue que esta instancia de participación formaba parte de un establecimiento de salud que funcionaba en un territorio donde la medicina ancestral estaba vigente y en la cual, el Estado venía desarrollando una política multicultural. Lo interesante en este segundo encuentro, fue la utilización del conocimiento antropológico en la definición y construcción del término interculturalidad por parte del profesional encargado de coordinar el Consejo. La reciente publicación especializada sobre "Prácticas de salud en las comunidades del Salar de Atacama: Hacia una etnografía médica contemporánea" (Chamorro y Tocornal 2005) se convirtió de pronto en la inspiración de lo que todos los participantes del CDL deberían entender por salud intercultural, a la vez que se constituyó en la base de legitimación de un tipo de conocimiento, en este caso científico, que deslegitimó cualquier otra fuente de experticia sobre la interculturalidad en el territorio. El concepto de salud intercultural sustentado en dicho artículo, reproducía una idea fuertemente instaurada por la red transnacional que financia a los organismos internacionales de la salud y que la definía como un espacio de intersección entre la salud formal representada por el consultorio (y la red asistencial a la que pertenece) y el sistema de salud indígena. ${ }^{11}$ Con esta homologación de las prácticas indígenas al modelo científico, se desconocía y negaba la multiciplicidad de itinerarios terapéuticos a las cuales la población atacameña ha tenido acceso (medicinas campesinas, medicinas alternativas, medicina religiosa, entre otras). ${ }^{12}$ Simultáneamente, se

\footnotetext{
${ }^{11}$ Para un ejemplo de estos análisis financiados y producidos desde los organismos multilaterales, ver Alderete (2002).

12 Parte de esta información venía siendo sistematizada por el pro-
} 
etnizaba un nuevo campo de intervención estatal: el de la salud ancestral que, desde una visión dominante, reducía y simplificaba las representaciones culturales de la salud de acuerdo al modelo hegemónico impuesto (en este caso el sistema biomédico). La reunión se convirtió de pronto en una capacitación sobre el sistema de salud indígena, sus clasificaciones, características, tomando como única referencia bibliográfica el estudio etnográfico mencionado. ${ }^{13}$ La exposición académica realizada por el profesional ahora autoproclamado experto de la interculturalidad, no solo marginó a los miembros del CDL de la posibilidad y el derecho a "participar" en la construcción del concepto de interculturalidad, sino que también transgredió el acuerdo respecto al tema de esa reunión: dialogar sobre la historia de la salud ancestral e intercultural en el territorio, previa al CDL. Surgieron así los primeros mecanismos de disciplinamiento que operaron a través de la participación impuesta y se revelaron los nuevos dispositivos a través de los cuales el Estado buscó legitimar un tipo de experticia y conocimiento.

\section{* La participación y el multiculturalismo a favor DE LA ETNICIDAD ATACAMEÑA}

A poco tiempo de transcurrido el proceso de constitución del CDL, los discursos sobre la participación, la ciudadanía y la democracia promovidos por los agentes estatales de la salud, van quedando atrás y comienzan a dar ejemplos en terreno de su "potencial tiránico" (Cooke y Kothari 2001: 14). El primero de estos ejemplos fue una reunión en la cual el coordinador del Consejo invitó a realizar un diagnóstico de la situación de salud de la población. Sin declararlo explícitamente, el equipo

yecto antes mencionado. Sin embargo, sus resultados no fueron considerados para reflexionar sobre las prácticas y representaciones de la salud y la enfermedad en el territorio. Este pequeño trabajo que fue parte del estudio epidemiológico financiado por Orígenes, se llamó "Estudio sociocultural" sobre las prácticas de la medicina ancestral y religiosa atacameña (Bolados y Moreno $2006 \mathrm{Ms}$ ).

${ }^{13}$ Lo complicado del artículo de Chamorro y Tocornal era que sus unidades de estudio las constituían cuatro localidades cuya composición sociodemográfica era sustancialmente diferente a las localidades más grandes de la comuna, lo que hacía que sus resultados fueran poco aplicables ante la compleja y diferenciada realidad local. de salud intentaba elaborar su plan anual en "forma participativa" y siguiendo las nuevas exigencias impuestas desde el Ministerio de Salud. Esto fue aclarado en la reunión siguiente, cuando el equipo de salud hizo una presentación del plan anual de salud de la comuna para el año 2007 ante el Consejo, argumentado que este documento contenía las propuestas priorizadas por la comunidad en el encuentro anterior. Pese a este modus operandi estatal, los miembros del CDL no presentaron ningún reparo y participaron corrigiendo y agregando aspectos no considerados en la presentación de esa planificación. Sin embargo, dos reuniones posteriores provocaron una reacción muy diferente e implicaron un vuelco respecto al camino hasta ahora transitado al interior del Consejo. Estas reuniones significaron la transición a un segundo momento del Consejo, el cual estuvo marcado por la entrada masiva de antiguos representantes de la Mesa de Salud creada por Orígenes y la fuga de los representantes de otras organizaciones y asociaciones locales, quienes vieron alejada la posibilidad de articular sus objetivos institucionales desde el CDL.

Se abrió así una nueva etapa del Consejo marcada por las tensiones y luchas por adjudicarse el control del espacio entre municipio/consultorio y el resucitado grupo de representantes de la antigua Mesa de Salud. El encargado del CDL empezó a recibir presiones de las autoridades municipales quienes, ante la activa presencia de un grupo considerable de dirigentes (varios de ellos contrarios a su política local), aprovecharon la salida del profesional y ubicaron al director del establecimiento como el nuevo responsable de su coordinación.

Las actividades del Consejo se retomaron en marzo de 2007 con un estratégico gesto de descentralización: el director del consultorio, ahora convertido en presidente del Consejo, convocó a una reunión en Toconao, a unos $40 \mathrm{~km}$ de la capital de la comuna. En esa oportunidad y con fondos del propio municipio, se trasladó a los paramédicos y representantes de los poblados de Socaire y Peine, lo cual fue interpretado en ese momento como una clara señal de compromiso con la participación real de las localidades de la comuna. Sin embargo, y a los pocos minutos de trascurrida la reunión, emergieron las verdaderas razones de los recursos invertidos para que la convocatoria tuviera éxito. El objetivo del director del consultorio era obtener

No $38 / 2009$

ESTUdiOS ATACAMEÑOS

Arqueología y Antropología Surandinas 
del Consejo la aprobación de una serie de proyectos de mejoramiento en infraestructura de las postas rurales de la comuna. Pese a que el Consejo deseaba fondos para asegurar la participación de representantes de cada comunidad, la participación se constituyó en un instrumento funcional a las prioridades del establecimiento y no a las ya establecidas por los miembros del CDL. El motivo de este tipo de ejercicio participativo se explicaba en parte, por las exigencias de los propios servicios de salud regionales, los que comenzaron a requerir en todos los establecimientos donde funcionaban instancias como el CDL, la firma y aprobación de la comunidad para la adjudicación de los recursos. Se observó así un uso instrumental de la participación, el cual generó rápidamente críticas y cuestionamientos entre los miembros del CDL. En esa oportunidad, teniendo en sus manos las bases del concurso que se buscaba aprobar, miembros del Consejo leyeron los objetivos del proyecto donde expresamente se manifestaba que esos recursos podían ser orientados tanto a la participación como a la infraestructura. Ante las contradicciones surgidas, la asamblea acordó enviar una carta al director del servicio planteando una crítica sobre el uso del poder en el traspaso de la información por parte de los funcionarios involucrados, y dejando expuesta la estrategia del consultorio y los organismos estatales en relación al traspaso de la información a la comunidad, cuya tramitación promovía una clase de participación express que no consideraba los tiempos, distancias, recursos y formas locales de organizarse. El carácter urgente de los concursos y proyectos y la nueva exigencia de que el Consejo respaldara con su firma las propuestas solicitadas por el consultorio, nuevamente pusieron en cuestión las formas de comprender la participación desde el Estado, principalmente en relación al manejo de la información y sus consecuencias en la toma de decisiones. Se observó así, una yuxtaposición de lógicas de comunicación entre los servicios estatales y las instancias comunitarias locales, así como también una lógica económica que convirtió al Consejo en un espacio para obtener y racionalizar recursos desde y hacia el Estado. La carta enviada por el Consejo al director del Servicio de Salud de Antofagasta manifestó otra manera de concebir la participación:

"Consideramos que la participación real se hace en base a una información fluida y anticipada que refleje las necesidades en sa- lud de la población y a una programación sistemática. Sin estas mínimas condiciones se hace a nuestro modo de ver muy difícil emprender un proceso de participación que dé cuenta de la situación de la salud a nivel comunal atendiendo a las características geográficas, étnicas y rurales que están comprometidas. Condiciones que al ser ignoradas muchas veces limitan y desincentivan la participación activa de los usuarios y afectan en su percepción negativa de los sistemas de atención de los servicios de salud existentes" (Acta del CDL, marzo 5 de 2007).

Este conflicto alertó sobre la necesidad de democratizar el Consejo a través de la elección de una directiva que brindara mayor autonomía y capacidad de autogestión en relación a los intereses del consultorio. Varios de quienes veníamos trabajando en salud en el territorio nos preguntábamos qué sentido tenía crear otro espacio de participación cuando ya existía la Subcomisión de Salud del ADI, la cual, además de contar con la presencia de los actores más importantes, se había constituido en el espacio oficial desde el cual se definía la distribución de los recursos estatales hacia la población. Sin embargo, la insistencia por convertir al Consejo en la instancia más representativa de la salud en la comuna, coincidía con el fin de reposicionar al consultorio en la comunidad después de los conflictos y tensiones provocados por la transición desde posta a consultorio. Los resultados de un estudio sobre percepción usuaria realizado por el propio municipio el año 2006, indicaban que quienes acudían al consultorio catalogaban la atención recibida como mala a regular y que, pese a las nuevas dependencias y al aumento de profesionales, la población seguía considerando deficiente la calidad de la atención, los sistemas de turnos inadecuados a la realidad territorial y excesivas las demoras en los tiempos de espera.

El segundo conflicto se produjo a raíz de una reunión extraordinaria a la cual el director del consultorio invitó a un grupo pequeño de representantes del Consejo. El motivo de la reunión era preparar la cuenta pública en salud que el consultorio debía rendir los días siguientes ante la comunidad y los organismos que financian la salud local, es decir, la Municipalidad y el Servicio de Salud Regional. En esta oportunidad y solo a días de realizarse este evento, el CDL decide no participar en la rendición de la cuenta y solicita presentar independientemente sus avances y dificultades. La respuesta 
no se hizo esperar: se concedieron cinco minutos para efectos de la participación de la comunidad en la cuenta pública.

Estos dos acontecimientos marcaron una fase del Consejo que se caracterizó por el movimiento de un modo impositivo de ejercer la participación desde la lógica estatal, hacia un modo participativo local más politizado y etnizado, el cual fue introducido por los representantes de la ex Mesa de Salud, instituidos como Asociación de Cultores desde el año 2006, y ahora incorporados al Consejo. En este período las reuniones se caracterizaron por una permanente lucha por apropiarse del espacio entre los representantes del municipio y la dirección del consultorio por un lado, y por el grupo de ex dirigentes de la Mesa por el otro, quienes vieron en esta instancia, una nueva oportunidad para instalar demandas pendientes en relación a la salud ancestral. Estas demandas cubrían tanto aspectos de la salud formal relacionados a la calidad y acceso de la atención, como aspectos relacionados al reconocimiento y valoración del sistema médico atacameño. Ambos tipos de demandas constituyeron en este período el centro de los debates y discusiones al interior del CDL, los que se materializaron en una propuesta para implementar una experiencia piloto en salud intercultural en el territorio. Las reuniones en esta segunda etapa del Consejo dejaron paulatinamente de ser dirigidas por el director del consultorio, cuyas acciones fueron neutralizadas por este nuevo grupo que en un corto lapso, consiguió reorientar los objetivos y propósitos del Consejo. Este contingente de excomulgados dela antigua MesadeSalud, algunos recuperadosenla Subcomisión de Salud e institucionalizados en la Asociación de Cultores, eran ahora los líderes y conductores principales de este espacio de participación social. Este segundo momento se caracterizó por la rememorización del proceso anterior impulsado por las acciones de Orígenes en el territorio y significó una reelaboración local de las formas de concebir y practicar la participación desde la agencia indígena atacameña representada en el CDL. La participación ahora significaba empoderamiento, lucha por el control del conocimiento médico indígena, capacidad de gestionar recursos, e incluso, apropiación física de algunos espacios en las nuevas dependencias del consultorio. La interculturalidad ya no solo aludía a las relaciones entre el sistema de salud formal y el sistema médico ancestral, sino y por sobre todo, implicaba compartir el poder y la producción de las diferencias dentro del nuevo campo de la salud intercultural construido por la política neoindigenista del Estado chileno.

Ya encauzadas las demandas indígenas de reconocimiento del sistema médico atacameño dentro del Consejo, se inició un tercer momento que coincidió con la implementación de la experiencia piloto en salud intercultural en el territorio. Se había obtenido la autorización del municipio para que una sanadora indígena atendiera en el consultorio una vez por semana. El triunfo de la agencia indígena respecto al cumplimiento de una antigua demanda de la salud ancestral y las estrategias de resistencias frente a la participación impuesta desde el Estado, se tradujeron en un despliegue de nuevos dispositivos de intervencionismo estatal. Nuevamente, la estrategia utilizada fue desconocer e ignorar los acuerdos anteriores y restaurar lo que hemos definido como "la lógica de la amnesia estatal" (Boccara y Bolados 2008). Ésta se realizó a través de una breve capacitación sobre "participación y democracia" a cargo de la funcionaria del servicio de salud, quien era la encargada del Programa de Participación Social del Servicio de Salud Regional.

\section{* Democracia y participación "en terreno": \\ LA LÓgICA DE LA AMNESia ESTATAL}

En un contexto de expectativas y de amplia convocatoria para dialogar respecto a los inicios de la experiencia piloto implementada en el consultorio, se programó una reunión extraordinaria del Consejo. El fin era tener un encuentro del CDL con el médico invitado a la charla, quien, desde los inicios de los años 90 trabajaba en experiencias en salud intercultural y complementaria en territorios mapuche y huilliche del sur de Chile. Pese a que el objetivo de la reunión ya había sido establecido, el lugar de encuentro fue literalmente "tomado" por la funcionaria del servicio de salud, quien había elegido ese mismo espacio para promocionar un nuevo proyecto llamado "El Consultorio Amigo" y realizar - sin comunicarlo previamente al Consejo-, una evaluación del funcionamiento del CDL. Instaladas las nuevas tecnologías de la burocracia estatal (Power Point, computador), la reunión se inició en un clima de desconcierto ante lo 
inesperado de la presencia de la funcionaria. Como ella misma explicó, su objetivo era invitar a los miembros del Consejo a formalizar este espacio a través de la creación de un reglamento interno que permitiera la elección de una directiva y que según sus palabras, "democratizara" al CDL. Es así como la funcionaria dio inicio a la reunión:

"Básicamente a mí me gustaría tratar algunas cuestiones que tienen que ver directamente con el funcionamiento del Consejo de Desarrollo...que está dentro de la política que ha realizado el ministerio [...]. Contarles cuál es el sentido de que exista el Consejo. El Consejo de participación al lado de cada establecimiento nuestro [...]. El objetivo fundamental es apoyar la gestión del establecimiento de salud en las distintas indoles que tienen que ver con competencias que puedan resolver diversos programas [...] hay algunas cosas que todavía nos quedan ir construyendo. Por ejemplo, un reglamento interno que vele por el funcionamiento democrático del Consejo, ¿qué significa un funcionamiento democrático? Que sean ustedes, los que participan en este Consejo, los encargados de elegir a los miembros participantes del mismo... y elegir a la directiva de este Consejo. En una primera etapa, [nombra al director del consultorio] asumió la directiva como para guiar un poco el desarrollo, pero una de las tareas que está pendiente por hacer, es la constitución de un reglamento interno que vele por el verdadero sentido de este Consejo de Desarrollo. ¿Cuál es la función más importante?, es la de asesorar al equipo de salud en las diferentes actividades relacionadas a salud que vayan en pos del beneficio de la misma comunidad. Tiene que ver con el ejercer una contraloría social... en esa figura y como se supone que va a dar una asesoría a la dirección del establecimiento no debería ser la directora la misma presidenta que dirige. Ustedes van a ser la voz, porque se supone que detrás de ustedes hay otras personas... Era un poco para invitarlos a hacer este ejercicio democrático y no olvidarnos que esto es una expresión de la comunidad en el consultorio para ir trabajando dentro del establecimiento [...]. Hay que pegarle una segunda vuelta... como hay una resolución, la idea es la marcha blanca... como usted señala en esta etapa más avanzada que se va desarrollando, la idea es que vayan teniendo más responsabilidades en la toma de decisiones... que de alguna manera se vayan empoderando de lo que significa el accionar de la sociedad en salud. La idea es invitarlos a hacer mucho más participativo el proceso" (Encargada de participación social, reunión del CDL, septiembre de 2007).

Pese a sus buenas intenciones de apoyar el desarrollo y avance del CDL, su discurso ignoró que éste venía fun- cionando activamente desde casi un año antes de su venida. Más aún, su propuesta de elegir a una directiva desconoció y deslegitimó a la ya elegida democráticamente por los miembros del Consejo, la que por las dificultades del propio director para delegar el poder y la información, no consiguió cumplir con su rol. El modus operandi reiterado de los agentes estatales evidenció el funcionamiento de un dispositivo del poder burocrático -amnesia estatal-, cuyo mecanismo de invisibilización de los acuerdos anteriores y la marcha blanca de los procesos participativos, se constituyó en la estrategia central del ritual de silenciamiento ejecutado por la mano todopoderosa del funcionario estatal.

Su breve pero intensa capacitación sobre "participación y democracia” planteó algunos puntos importantes. Para empezar, su charla se realizó violentando el programa definido por el propio Consejo. Al parecer, su calidad de encargada del Programa de Participación Social le otorgaba la autoridad necesaria y la experticia adecuada para intervenir y modificar los acuerdos del CDL. Las réplicas de los miembros del Consejo no se hicieron esperar y la discusión se centró en el tipo de participación al que se deseaba acceder o construir desde el Consejo. Se preguntó qué asesoramiento, apoyo o contraloría se esperaba de los representantes del Consejo, cuando las bases que dieron origen a esta instancia ya eran bastantes antidemocráticas. Luego, las palabras de la funcionaria dejaron entrever que el período hasta ahora transitado correspondía a la infancia del Consejo y que era el momento para inaugurar la etapa de la adultez. De este modo se desconocieron las acciones anteriormente realizadas por el Consejo, considerándoselas parte de una etapa previa; en tanto, la nueva etapa se caracterizaría por la capacidad de los miembros del CDL para asumir más responsabilidades y tener mayor participación en la toma de decisiones. En tan solo cinco minutos la capacitación reveló en su máxima expresión las confusiones y ambigüedades en las que queda entrampada la participación social cuando ésta es apropiada por el Estado. Una de las dirigentes atacameñas lo expresó claramente en estos términos:

"De verdad yo al comienzo como que todavía estoy como algo confusa... a qué lleva este Consejo realmente... ya que sea siempre se están creando como instancias. Por ejemplo la mesa temática del ADI... tenemos ésta. [...]. Yo a eso le temía, nada más que 
para venir a cuestionar cómo se está manejando el consultorio y también así las postas rurales... pero nunca supe para qué se ha creado este Consejo. Al comienzo se nos dijo que no se manejan recursos... y generalmente va todo por los recursos, porque aquí nosotros traemos nuestras necesidades. Lo mismo en la mesa temática... nunca se nos dice el dinero que hay. De todas maneras igual me incorporé... yo nunca fui invitada... cuando vi que venían los socios empezó a tener más importancia la participación de la Asociación" (Presidenta de la Asociación de Cultores y actual dirigente indígena del Consejo de Pueblos Atacameños).

De pronto, el tema de discusión de la reunión dejó de ser exclusivamente la participación social en el Consejo y se extendió a todas las otras formas de participación promovidas por el Estado en el territorio. Específicamente la crítica se dirigió al modo de operar de los organismos estatales para constituirse en los administradores de la participación en salud. Desde esta perspectiva, no solo era cuestionado el tipo de "participación impuesta" desde la dirección del consultorio y el departamento de salud municipal, o las prácticas de "participación express" del Servicio de Salud. Lo que se estaba poniendo en cuestión, era el modo de apropiación ilegítima del poder y la autoridad ejercida por los organismos estatales a través de la participación social. La disputa giró sobre quiénes o quién y qué organismo o grupo debía adjudicarse la autoridad/legitimidad respecto de los contenidos y las metodologías a implementarse en el Consejo. Esta discusión era especialmente importante para las autoridades municipales quienes, como autoridades políticas elegidas democráticamente, se adjudicaban la administración jurídica y financiera del consultorio. Por otra parte, la encargada de participación social del Servicio de Salud se atribuía la autoridad técnica y representación política a nivel nacional de la política de salud del gobierno, la que, además de financiar y traspasar recursos al municipio, se constituía en el ente oficial responsable de velar por la correcta y buena implementación de las orientaciones de la política pública en salud. Desde otra perspectiva, los propios miembros del Consejo reivindicaban el poder y la autoridad para determinar sus prioridades en salud y el derecho a administrar este nuevo campo de la salud intercultural. Las últimas intervenciones en esta reunión se transformaron de algún modo en un cierre del proceso, y revelaron que las luchas entre los diversos agentes involucrados formaban parte de un campo mucho más amplio y conflictivo: el de la lucha por la definición legítima y dominante de las diferencias sociales y étnicas, como también de los diversos capitales (económicos, sociales, culturales y políticos) asociados a éstas. ${ }^{14}$

Los efectos más directos de este tipo de ejercicio del poder a través de la participación se comenzaron a vislumbrar: por una parte, el agotamiento y la desconfianza de los miembros del Consejo frente a estas estrategias; por otra, la neutralización de los logros alcanzados y la desmovilización de las organizaciones indígenas locales. La práctica reiterada de esta lógica de amnesia estatal y las resistencias generadas entre los miembros del Consejo, desembocaron en un paréntesis en las actividades de éste. Sin embargo, los conflictos volvieron e incluso se agudizaron en el período siguiente, cuando el municipio intentó nuevamente tomar el control de la situación y frenar la experiencia piloto iniciada en el consultorio. $\mathrm{Al}$ parecer, mientras este grupo de dirigentes permaneciera en el CDL o cualquier otra instancia, sus organizaciones no serían reconocidas al menos por el municipio y sus aliados del Programa Orígenes y la CONADI. Se marcó así el inicio de una nueva etapa de intervención del poder burocrático a través del gobierno local, quienes de aquí en adelante apelarán permanentemente a su calidad de autoridades políticas y étnicas en el territorio.

\footnotetext{
14 Poco tiempo después apareció un documento que dejaba constancia del motivo oficial de la presencia de la funcionaria en la reunión del CDL: ésta se explicaba por la "evaluación" del CDL, que debía realizar como encargada de participación del Servicio. El documento estaba segregado en cinco celdas correspondientes a los ítemes de: a) objetivo específico; b) requisito técnico; c) medio de verificación; d) ponderación; y e) resultado de cumplimiento ponderado. De los 12 puntos evaluados por la funcionaria, y sin requerir en esa y en ninguna oportunidad, la participación de los miembros del Consejo, tras una mágica ecuación cuantitativa, el CDL ponderó un total de $85 \%$ de logros que, al parecer, constituyó un éxito no conocido por sus propios protagonistas. Junto a este documento y con la misma fecha, apareció otro titulado Plan de Trabajo Anual del Consejo de Desarrollo Local, cuyas dos hojas dirigidas de manera oficial al Servicio de Salud correspondiente y firmadas por el director del establecimiento, contenían un informe de las metas y acciones del CDL donde se describían las actividades a las cuales el consultorio habría "invitado a participar" a la comunidad en este tiempo.
} 
* La etnogubernamentalización a través de la "PARTICIPACIÓN POR DECRETO"

La confluencia de los procesos de democratización y neoliberalización en un contexto de re-emergencia étnica y multiculturalismo como el que se ha dado en Latinoamérica y específicamente en Chile, parecieran favorecer un nuevo tipo de ejercicio del poder a través de la participación social. Este nuevo arte de gobierno implementado por la política indígena e intercultural de estos años, y la nueva y más sofisticada clase etnoburocrática nacida con ella, ha puesto las bases para la extensión y profundización de los mecanismos de regulación desde el Estado hacia las poblaciones indígenas nacionales. La participación social re-emerge en este nuevo escenario, cumpliendo una doble función: como instancia de fiscalización y/o control ("contraloría") de la sociedad respecto de las acciones del Estado, al mismo tiempo que una fiscalización del Estado hacia las poblaciones originarias a través de sus agentes, servicios y programas. La participación social contribuye a la emergencia de una ciudadanía delegada por y desde el Estado, quien otorga a los individuos y comunidades el nuevo estatus de usuarios y consumidores de los servicios públicos entregados. En los casos donde el empoderamiento, la participación y el ejercicio de esa ciudadanía excede los límites permitidos, estas atribuciones rápidamente experimentan reelaboraciones y reconfiguraciones desde los organismos y servicios representantes del poder burocrático. De esta forma, la práctica de la participación social queda atrapada en un tipo de lógica de mercado mediante el cual se pretende incorporar a los ciudadanos en el juego perverso del "ya, pero" del multiculturalismo neoliberal (Hale 2004).

La democracia y la participación aparecen entonces trabajando a favor de la neoliberalización de lo social y bajo una racionalidad instrumental de medios afines que promueve una lógica de la agregación. Esta idea, expuesta por Bourdieu (2005), cuestiona el tipo de pensamiento matemático y estadístico aplicado a lo social y/o cultural, a través de la homologación de una opinión como igual a un acto de participación y a una voluntad. Este tipo de lógica que privilegia la suma cuantitativa de los sujetos en su calidad de "representantes que representan a sus representados en representación" de no sabemos qué, ocultan las reales condiciones de producción y expresión de esa opinión y voluntad. Esta interpretación equívoca, sin em- bargo, emerge como una de las formas más generalizadas y dominantes de comprender, ejercer y evaluar la participación desde el Estado (Bello 2007). La importancia y necesidad de firmar la famosa "lista de asistencia" de las reuniones organizadas por los organismos y programas del Estado, lo avalan. La creencia en la ecuación de que a más espacios de participación mayores oportunidades, justifica el bombardeo frecuente del Estado hacia sectores determinados de la sociedad a través de la proliferación de reuniones, encuentros, talleres y recursos que reducen la comprensión del acto democrático a una suma de votos y voluntades. Se ignora e invisibiliza otras formas de organización local existentes y se impone un tipo de lógica sociopolítica que niega y naturaliza las diferencias sociales y económicas, reproduciendo las posiciones de subalternidad de los sujetos y grupos en el espacio social. El resultado de la triangulación de los procesos de ampliación de ciudadanía, de democratización de la sociedad y la apertura de nuevos espacios de participación "confluyen perversamente" (Dagnino 2006: 401) en el efecto de encubrir las condiciones a partir de las cuales se opina y participa (p.e., las redes de clientelismo que operan vía proyectos y recursos del municipio hacia las comunidades en el territorio). De esta forma, la participación despliega su potencial tiránico a través de sus efectos de "pacificación o subyugación" social. El avance de las democracias liberales que se basan en una lógica estadística de la mayoría, no hace más que reforzar la lógica neoliberal que sobrepone una lógica de las minorías en los acuerdos colectivos: "la lógica de la agregación que está en el centro del pensamiento estadístico y también económico, supone unas condiciones de validez que implican al mismo tiempo unos límites" (Bourdieu 2005: 74). La acción colectiva fundada sobre la delegación se ve entonces amenazada por la apropiación usurpadora de quien domina el lenguaje y la experticia. En este caso, son los expertos de la participación social quienes logran atribuirse algún tipo de legitimidad sirviéndose del discurso autorizado del multiculturalismo y la etnicidad. A la vez, son los mismos agentes quienes se apropian ilegítima pero legalmente de la capacidad de delegar u otorgar el estatus de representante, ciudadano, usuario.

La participación social revela que sus contradicciones no provienen solo de las herramientas metodológicas que se utilizan para implementarla, sino que sus deficiencias son sistémicas y demandan una reflexión teórica y política aún 
pendiente en el mundo de los practicantes o impulsores de la participación (Cooke y Kothari 2001). Por otro lado y vía participación, se reaviva el mito de la comunidad y se crean nuevos sistemas de representaciones de éstas como algo homogéneo, estático, donde las personas comparten intereses y necesidades comunes que justifican nuevas intervenciones de gobierno. El concepto de capital social reelaborado por el aparato del desarrollo ha sido esencial en la reconfiguración neoliberal de la participación, el cual la ha incorporado en el ámbito de las elecciones de los medios de los individuos. Se transforma así en recurso colectivo y político fundado en valores compartidos de asociatividad que la convierten en "una propiedad necesaria para hacer que la calidad democrática de una sociedad encuentre un sostén que las instituciones representativas, por sí solas, no podrían asegurar" (Pisorno 2003: 22). La participación social se convierte así en la estrategia clave para fortalecer el capital social de determinados grupos sociales y culturales, y en el eje central de las intervenciones focalizadas que promueven actualmente las agencias multilaterales y donantes.

Las características dadas a la participación por los agentes estatales de la salud, revelan además, la persistencia de una visión y división del mundo social en términos de "grados de desarrollo" (Escobar 1995). Esta idea de grado sobre la cual se legitimó un tipo de desarrollo que separó los mundos en primero, segundo y tercero, etc., entre países subdesarrollados, en vías de desarrollo y desarrollados, como también entre países centrales y periféricos, parece todavía estar presente en las prácticas de la participación. Se continúa reproduciendo un cierto positivismo cultural en las actuales intervenciones del desarrollo, que reducen y simplifican la complejidad social en términos de causalidad. El Consejo de Desarrollo Local, desde la perspectiva estatal, se constituyó un espacio representativo de toda la realidad social atacameña. Es decir, sus miembros se convirtieron en los representantes de sus comunidades a través de los cuales los agentes estatales de la salud establecían relaciones formales con la comunidad. Sin embargo, el acto de constitución de este nuevo espacio social y sus agentes se llevó a cabo a través de la invisibilización del pasado participativo local. En una dinámica todavía paternalista, estos funcionarios pensaban, al parecer, que solo reunirse constituía participación y que los miembros del Consejo requerían de su apoyo para emprender el camino hacia la participación. Era imprescindible un período de crianza de parte de la autoridad para recién delegar mayor responsabilidad en la toma de decisiones. El ejercicio en terreno de la participación se constituye de este modo en un ejemplo concreto donde observar cómo el Estado comprende y legitima la naturaleza de su autoridad. La espacialización que el Estado produce a través de su poder burocrático ya no solo lo ejerce mediante sus instituciones y agentes formales; sino, y esto es lo nuevo, a través de los propios individuos que son obligados a autodisciplinarse y responsabilizarse. Parafraseando a Ferguson y Gupta:

“...existe un nuevo tipo de gobernamentalidad transnacional que no reemplaza al sistema anterior del Estado nación, sino que coexiste con ésta. El mismo Estado produce espacios y escalas jerárquicas donde es posible observar su extensión (horizontalidad) y profundidad (verticalidad), siendo estas mismas escalas legitimadas y substancializadas en la vida diaria a través de una multiplicidad de situaciones concretas alrededor del mundo" (2005: 121; traducción de la autora).

Con estos mecanismos de visibilización e invisibilización, memoria y olvido, delegación y fiscalización, legitimación y desautorización, es que se despliegan técnicas de poder ya no solo sobre el cuerpo de un individuo (programas de vacunación, medicalización, control reproductivo, etc), sino una nueva forma de poder a nivel de la población. Siguiendo a Foucault, podría decirse que se ha pasado de la anatomopolítica a la biopolítica o biopoder. Un poder que no se concentra en un solo lugar ni en una sola institución, sino que se ramifica y reproduce eficazmente a través de diversas técnicas y agentes. Goverment o gobierno en el sentido foucaultiano significa aquellas formas más o menos calculadas de pensar y actuar que tienen como objetivo modelar, regular o manejar el comportamiento de los otros. El biopoder significa hacerse cargo de la vida desde el poder político, donde el gobierno aparece asignándose a sí mismo el deber de administrar los cuerpos y la vida colectiva. Se trata de una nueva comprensión del poder político moderno que Foucault (2000) denominó governmentality.

El Consejo aparece en este contexto como una instancia para la acción de la sociedad civil y un ámbito intermedio entre el sector público (Estado) y la sociedad (ciudadanía), cuyo potencial de organización o capital

$\mathrm{N}^{\circ} 38 / 2009$

ESTUdios ATACAMEÑOS

Arqueología y Antropología Surandinas 
social se plantea como una condición obvia y evidente. La participación en este proceso queda despolitizada y naturalizada dentro del campo de lo social, promoviendo la autorresponsabilización a través del discurso del autocuidado. Es el nuevo orden social, político y económico construido por el neoliberalismo que ha modificado sustancialmente los roles de los agentes sociales involucrados. En este campo se advierte la confluencia de procesos divergentes tales como: la ubicuidad del Estado en determinados ámbitos y su total retiro en otros, el protagonismo de los organismos internacionales de financiamiento que perfeccionan un modelo poco participativo mientras colaboran en revoluciones verdes (Breton $2003 \mathrm{Ms}$ ), o bien, mediante la propia participación de las organizaciones indígenas vía proyectos de etnodesarrollo.

Las estrechas relaciones entre participación y neoliberalismo van quedando a la luz, convirtiéndola en una estrategia de reclutamiento de mano de obra gratuita que hace más eficaz la administración de los pocos recursos del presupuesto público en salud. A través de la participación social se reclutan a individuos o grupos para que cumplan la función de asesores y vigilantes ad honorem. Se otorgan módicas cuotas de recursos e información (sin decisión) frente a las cuales la sociedad debe responder con responsabilidad (autocuidado) y empoderamiento (participativos y activos). La participación social en la perspectiva del ejercicio de una nueva ciudadanía cultural, revela no solo las condiciones establecidas en las que se pretende promover, sino y también la interpretación neoliberal bajo la cual se está construyendo al ciudadano de mercado (Schild 2000) o al indígena-proyecto (Boccara 2007). Una red que atrae tanto a los Estados transnacionalizados en su papel de manager, a los organismos internacionales que fabrican políticas de ajustes con sus paralelos paliativos a través de programas focalizados, como a una élite indígena cada vez más involucrada en esta nueva etnogubernamentalidad neoliberal.

\section{* Referencias citadas}

ALDERETE, E., 2002. Saludy pueblos indígenas. Abya-Yala, Quito.

BID/MIDEPLAN, 2001. Reglamento operativo. Componente salud. $\langle$ www.origenes.cl〉.

BELLO, A., 2007. El Programa Orígenes y la política pública del gobierno de Lagos hacia los pueblos indígenas. En El Gobierno de Lagos, los pueblos indígenas y el nuevo "trato". Las paradojas de la democracia chilena, N. Yáñez y J. Aylwin (Eds.), pp. 193-220. LOM, Santiago.

BOCCARA, G., 2007. Etnogubernamentalidad. La formación del campo de la salud intercultural en Chile. Chungara, Revista de Antropología Chilena 39 (2):185-207.

BOCCARA, G. y P. BOLADOS, 2008. Dominar a través de la participación. Memoria Americana 16 (2). En prensa.

BOLADOS, P. y V. MORENO, 2006 Ms. Caracterización de las prácticas de la medicina tradicional y religiosa atacameña. Documento realizado en el marco del proyecto Apoyo al Diseño de un Modelo de Atención y Gestión Intercultural en la I y II Regiones, San Pedro de Atacama.

BOURDIEU, P., 2005. El misterio del ministerio. De las voluntades particulares a la voluntad general. En El misterio del ministerio. Pie- rre Bourdieu y la política democrática, L. Wacquant (Ed.), pp. 71-79. Editorial Gedisa, Barcelona.

BRETON, S. V., 2003 Ms. Neoliberalismo, etnicidad y etnofagia en América Latina. La experiencia de los Andes del Ecuador. Ponencia presentada en Meeting of the LASA, Dallas.

\section{CENSO 2002. www.ine.cl}

CHAMORRO, A. y C. TOCORNAL, 2005. Prácticas de salud en las comunidades del Salar de Atacama: Hacia una etnografía médica contemporánea. Estudios Atacameños 30: 117-134.

COOKE, B. y U. KOTHARI, 2001. The case for participation as tyranny. En Participation: The new tyranny? E. Cook y U. Kothari (Eds.), pp. 1-15. Zed Books, Londres y Nueva York.

DAGNINO, E., 2006. Concepciones de la ciudadanía en Brasil: Proyectos políticos en disputas. En Ciudadanía, sociedad civil y participación política, I. Cheresky (Ed.), pp. 387-410. Miño y Dávila Editores, Madrid.

ESCOBAR, A., 1995. Encountering development. The making and unmaking of the Third World. Princeton University Press, Princeton.

FERGUSON, J. y A. GUPTA, 2005. Spatializing States: Toward an

Arqueología y Antropología Surandinas 


\section{Paola Bolados}

ethnography of neoliberal governmentality. En Anthropology of modernity. Foucault, governmentality and life politics, X. Inda (Ed.), pp. 105-131. Blackwell Publishing, Oxford.

FOUCAULT, M., 2000. Power. The New Press, Nueva York.

HALE, C. R., 2004. Rethinking indigenous politics in the era of the indio permitido. NACLA, Report on the Americas 38 (2): 1-11.

LAURIE, N., A. ROBERT y S. RADCLIFFE, 2005. Ethnodevelopment: Social movements, creating experts and professionalising indigenous knowledge in Ecuador.Antípode 37 (3): 470-496.
PALEY, J., 2001. Marketing democracy. Power and social movement in postdictatorship Chile. University of California Press, Berkeley, Los Angeles.

PISORNO, A., 2003. Por qué pagamos la nafta. Por una teoría del capital social. En El capital social. Instrucciones de uso, A. Bagnasco, F. Piselli, A. Pizzorno y C. Triglia (Eds.), pp. 21-47. Fondo de Cultura Económica, Buenos Aires.

SCHILD, V., 2000. Neo-liberalism's new gendered market citizens: The "civilizing" dimension of social programmes in Chile. Citizenship Studies 4 (3): 275-305. 